Abstract AB1148 - Table 1

\begin{tabular}{|l|l|l|l|l|l|}
\hline Case & $\begin{array}{l}\text { Sex/ Age } \\
\text { (years) }\end{array}$ & $\begin{array}{l}\text { Underlying } \\
\text { disease }\end{array}$ & Laterality & $\begin{array}{l}\text { Immunosuppressive drugs } \\
\text { before biologic therapy }\end{array}$ & Biologic therapy \\
\hline 1 & $\delta / 25$ & Behçet's disease & Right & MTX, CyA & ADA \\
\hline 2 & $\delta / 43$ & $\begin{array}{l}\text { Neuromyelitis } \\
\text { optica }\end{array}$ & Bilateral & AZA & RTX \\
\hline 3 & $\delta / 14$ & Neuroretinitis & Bilateral & MTX & ADA \\
\hline 4 & $\$ / 56$ & SLE & - & $\begin{array}{l}\text { HYRROXYCHLORIQUINE, } \\
\text { MMF, CFM }\end{array}$ & RTX \\
\hline 5 & $\$ / 29$ & Idiopathic & Right & AZA & TCZ \\
\hline 6 & $\$ / 26$ & Idiopathic & Bialteral & AZA & TCZ \\
\hline 7 & $\$ / 43$ & $\begin{array}{l}\text { Relapsing } \\
\text { polychondnitis }\end{array}$ & Bialteral & MTX, CFM & IFX, TCZ \\
\hline 8 & $\delta / 39$ & Behçęt's disease & Right & MTX; MMF & IFX \\
\hline
\end{tabular}

MTX: methotrexate, CyA: cyclosporine A, AZA: azathioprine, CFM: cyclophosphamide, MMF: mycophenolate, ADA: Adalimumab, RTX: rituximab, TCZ: tocilizumab, IFX: infliximab.

Conclusions: This study shows that treatment with biologic drugs, including antTNF drugs, in NION associated to IMIDs, refractory to conventional treatment, seems to be effective. These results must be confirmed in prospective and randomised trials.

Disclosure of Interest: None declared

DOI: 10.1136/annrheumdis-2018-eular.5485

\section{AB1149 CYSTIC FIBROSIS AND INFLAMMATORY ARTHRITIS REQUIRING IMMUNOSUPPRESSION: A WORRYING COMBINATION?}

M.E.T. Ibrahim ${ }^{1}$, E. Clarke ${ }^{1,2}$, K. Martin ${ }^{1}$, D. Peckham ${ }^{3}$, A. Jones ${ }^{1}$, A. Horsley ${ }^{1,2}$, P. Watson ${ }^{1}$, J.E. Freeston ${ }^{3}$. 'Manchester University NHS foundation Trust, Manchester, UK; ${ }^{2}$ University of Manchester, Manchester, ${ }^{3}$ Leeds Teaching Hospitals NHS Trust, Leeds, UK

Background: Inflammatory arthritis is a recognised complication of cystic fibrosis (CF) with an estimated prevalence of $2.3^{[i]}$ to $8.5 \%$ [ii] of CF patients. Cystic fibrosis associated arthritis (CFA) constitutes the majority of this, but other there may be other co-morbid rheumatic disease. Concerns about use of immunosuppression in the context of chronic pulmonary infection, and consequent risk of destabilisation, may limit use of these medications when clinically indicated. Immunosuppressive therapy is used in patients with CF lung disease who have inflammatory rheumatic disease, inflammatory bowel disease, or who have had a liver transplant for CF-related liver disease. Some data on those receiving immunosuppression post-transplant has been published and reassuringly reported fewer courses of intravenous antibiotics following transplant. ${ }^{[i i i]}$ Reports of immunosuppressants being used in other contexts, including arthritis, are more sporadic.

Objectives: To assess prior use and safety outcomes of immunosuppressant therapy in adults with CF.

Methods: A retrospective case note review of patients with CF receiving disease modifying anti-rheumatic drugs from 2 large adult CF centres (total $>700$ patients) from electronic records spanning 3-10 years.

Results: 41 patients were identified: 7 post liver transplant, 1 with inflammatory bowel disease, 1 with IgA nephropathy; 32 with inflammatory arthritis.

Abstract AB1149 - Table 1

\begin{tabular}{lccc}
\hline Medication & $\begin{array}{c}\text { Number of } \\
\text { patients }\end{array}$ & $\begin{array}{c}\text { Cumulative } \\
\text { months of } \\
\text { treatment }\end{array}$ & $\begin{array}{c}\text { Stopped due to } \\
\text { side effects }\end{array}$ \\
\hline Azathioprine & 4 & 239 & 0 \\
Hydroxychloroquine & 27 & 726 & 3 \\
Sulfasalazine & 7 & 98 & 3 \\
Tacrolimus & 7 & 900 & 0 \\
Methotrexate & 6 & 192 & 1 \\
Cyclophosphamide & 1 & 1 & 0 \\
Etanercept (with methotrexate, & 1 & 7 & 0 \\
sulfasalazine, hydroxychloroquine) & & & \\
\hline
\end{tabular}

There was one possible case of increased pulmonary exacerbation associated with methotrexate; they remained on treatment at the time of the study. There was no evidence that immunosuppression resulted in a fall in lung function necessitating cessation of treatment in any of these cases. Three patients stopped hydroxychloroquine and 1 patient stopped methotrexate due to non-respiratory side effects. Four of 7 patients responded to treatment with sulfasalazine for inflammatory arthritis, 3 stopped due to non-respiratory side effects.

Conclusions: No patients had immunosuppression stopped because of deterioration in lung disease. Steroids were not included in this analysis because duration and dose varied widely. However, it is important to note that they are frequently used in CF (particularly for allergic bronchopulmonary aspergillosis). Indeed $14 \%$ of all CF patients in these centres have had steroids in the last 6 months, of whom nearly half received a course of more than 6 months duration.
Whilst our results are reassuring, the numbers remain small. Decisions must be made in conjunction with the multidisciplinary team, but CF in itself should not delay or stop treatment with immunosuppression where it is indicated.

\section{REFERENCES:}

[1] Rush, P. J., A. Shore, et al. (1986).

[2] Bourke, S., M. Rooney, et al. (1987).

[3] Dowman, J. K., D. Watson, et al. (2012).

Disclosure of Interest: None declared DOI: 10.1136/annrheumdis-2018-eular.2992

\section{AB1150 1 THE EUROPEAN REFERENCE NETWORK ON RARE AND COMPLEX CONNECTIVE TISSUE AND MUSCULOSKELETAL DISEASES: ERN RECONNET}

M. Mosca ${ }^{1}$, M. Cutolo ${ }^{2}$, S. Badreh ${ }^{3}$, S. Bombardieri ${ }^{4}$, G. Burmester ${ }^{5}$, J.

E. Fonseca ${ }^{6}$, C. Frank ${ }^{7}$, I. Galetti ${ }^{8}$, E. Hachulla ${ }^{9}$, F. Houssiau ${ }^{10}$, U. Müller-Ladner ${ }^{11}$, M. Schneider ${ }^{12}$, V. Smith ${ }^{13}$, J. van Laar ${ }^{14}$, on behalf of ERN ReCONNET Coordinators and HCPs. ${ }^{1}$ Azienda Ospedaliero Universitaria Pisana, Pisa; ${ }^{2}$ IRCCS AOU San Martino, Genova, Italy; ${ }^{3}$ Lupus Europe, Romford, UK: ${ }^{4}$ University of Pisa, Pisa, Italy, ${ }^{5}$ Charité Universitätsmedizin Berlin, Berlin, Germany, ${ }^{6}$ Centro Hospitalar de Lisboa Norte, Lisbon, Portugal; ${ }^{7}$ Bindweefsel, Koersel; ${ }^{8}$ Federation of European Sleroderma Associations (FESCA), Brussels, Belgium; ${ }^{9} \mathrm{CHRU}$ de Lille, Lille, France; ${ }^{10}$ University Hospitals Saint-Luc, Brussels, Belgium; ${ }^{11}$ Kerckhoff Klinik, Bad Nauheim; ${ }^{12}$ Universitätsklinikum Düsseldorf, Düsseldorf, Germany;

${ }^{13}$ University Hospital Ghent, Gent, Belgium; ${ }^{14}$ University Medical Center Utrecht, Utrecht, Netherlands

Background: Set up under the European Union (EU) directive on patients' rights in cross-border healthcare (2011/24/EU), European Reference Networks (ERNs) on rare and complex diseases are aimed at connecting healthcare providers (HCPs) across different EU Countries to tackle complex and rare medical conditions that require highly specialised treatment. ERN ReCONNET, endorsed by EULAR, and approved for rare and complex connective tissue diseases (CTDs), aims at developing a framework for the delivery of high quality, innovative, sustainable and equitable standard of care and practice for better access to care of European patients.

Objectives: To report the activities of ERN ReCONNET during the first 10 months of work

Methods: ERN ReCONNET is composed of 26 HCPs from 8 EU Countries: Belgium, France, Germany, Italy, Netherlands, Portugal, Romania and Slovenia Patients involvement is ensured by the ERN ReCONNET European Patients Advocacy Group, included in the activities of the ERN. The diseases covered are divided into 3 main thematic areas: rare CTDs (systemic sclerosis, mixed CTD, idiopathic inflammatory myopathies, antiphospholipid syndrome, undifferentiated CTD, IgG4 related diseases, relapsing polychondritis), complex CTDs (SLE, Sjogren's Syndrome), hereditary connective tissue diseases (Ehlers-Danlos syndrome). Senior and Junior Coordinators for each disease were selected. The scientific activities of ERN ReCONNET officially started in Vilnius in March 2017, where the 24 ERNs have been formally launched.

Results: The scientific activities of the first year were mainly focused on existing clinical practice guidelines (CPGs). The first phase was aimed at identifying the scientific publications, selecting them by evaluation of titles and abstracts, and by reviewing the full texts. More than 6.000 publications have been screened. The second step was to review critically the articles according to the principles of the AGREEII flow-chart. This work allowed to identify CPG for the majority of the diseases covered by ERN ReCONNET, as well as unmet needs, in particular for the rarest diseases (IgG4 related diseases, relapsing polychondritis, mixed CTD). Good progress has also been made in the field of IT, in which ERN ReCONNET was mainly focused on the use of the Clinical Patients Management System webplatform, designed for the interactive discussion of difficult clinical cases. Notably, the creation of ERN website is being co-designed by all Networks stakeholders.

Conclusions: The ERN ReCONNET will significantly improve the clinical approach to rare and complex CTDs, promoting an improvement of the quality of the specialised care provided to patients, of the activity of the physicians, the empowerment of the patients sharing expertise and promoting the interaction among EU HCPs. All these activities are addressed to create a highly specialised network, in which the knowledge travels rather than the patient.

Disclosure of Interest: None declared

DOI: 10.1136/annrheumdis-2018-eular.6341 